\title{
A EDUCAÇÃO DO CAIPIRA: SUA ORIGEM E FORMAÇÃO
}

\author{
Judas TAdeu DE CAMPos*
}

\begin{abstract}
RESUMO: Este texto busca compreender como se originou e se compõe o "currículo" que durante séculos foi utilizado pelos caipiras para transmitir sua cultura. Procuro mostrar que esse processo educativo se realizava por meio do trabalho cotidiano, da religiosidade e da solidariedade grupal. E também o impacto que o êxodo rural vem causando nesse tipo de cultura. Este estudo é uma pesquisa qualitativa, com um estudo de caso etnográfico, com um olhar holístico, numa perspectiva crítica e descritiva. Desenvolvi as análises durante a investigação em teorizações progressivas, num processo interativo com a coleta de dados. A conclusão procura mostrar o impacto do êxodo rural e da escola na cultura caipira, assim como as consequências das atuais políticas educacionais no meio rural.
\end{abstract}

Palavras-chave: Cultura caipira. Currículo educacional informal.

\section{THE CAIPIRA EDUCATION: ORIGIN AND FORMATION}

ABSTRACT: This text attempts to understand the "curriculum" that, for centuries, has allowed caipiras to transmit their culture. It tries to show that this educational process involved daily work, religiosity and group solidarity. It is a critical qualitative research that brings forward an ethnographic case from a holistic perspective. Analyses were progressive theorizations developed during the research, in interaction with fieldwork. In its conclusion, this paper highlights the impact of rural migration and school on the caipira culture and as well as of the consequences of the current education policies in rural areas.

Key words: Caipira culture. Informal curriculum.

\section{L'ÉDUCATION CAIPIRA: SON ORIGINE ET FORMATION}

RÉSUMÉ: Ce texte cherche à comprendre comment a surgi et s'est composé le "cursus" qui, pendant siècles, a été utilisé par les caipiras (paysans) pour transmettre leur culture. Il entend montrer que ce processus éducatif passait par le travail quotidien, la religiosité et la solidarité de groupe. Il examine également l'effet de l'exode rural sur ce type de culture. Dans une perspective critique et descriptive, cette recherche qualitative porte un regard holistique sur un cas ethnographique. Les analyses ont été réalisées pendant la

Doutor em Educação, professor e pesquisador no Instituto Básico de Humanidades da Universidade de Taubaté (UnITAU). E-mail: j.t.campos@uol.com.br 
recherche, par théorisations progressistes, en un processus d'interaction avec la collecte de données. La conclusion cherche à montrer les conséquences de l'exode rural et de l'école sur la culture caipira, ainsi que les résultats des politiques d'éducation actuelles en milieu rural.

Mots-clés: Culture paysanne. Cursus officieux.

\section{Procurando caminhos}

$\mathrm{N}$ o Alto Paraíba, sub-região do Vale do Paraíba paulista, que fica entre os contrafortes da Serra do Quebra-Cangalha e o alto da Serra do Mar, ainda se encontra um modo de vida diferente. Compreende cinco municípios que, juntos, têm menos de 50 mil habitantes. Ali ainda existem diversas manifestações culturais que se originaram no período da colonização. Sobrevivem festas ancoradas no devocionário popular, comidas típicas e outros costumes que há cerca de 100 anos eram muito comuns por todo o Estado de São Paulo, mas que, em razão de diversos fatores, atualmente são muito raros ou até mesmo acabaram desaparecendo. Brandão (1983) afirma que no Alto Paraíba está o último bolsão de um modo de viver tipicamente paulista, que ficou conhecido como cultura caipira.

Esta pesquisa busca a compreensão da maneira pela qual os portadores da cultura caipira transmitem as representações de seu imaginário e o significado de seus valores e das tradições acumuladas ao longo dos séculos. Procura também compreender o porquê de esses instrumentos culturais serem relevantes para os processos de socialização e adaptação ao meio em que vivem. De que maneira um grupo social que durante tanto tempo viveu praticamente sem contato com material escrito pode conservar tantos instrumentos? Como foi composto seu "quadro curricular" para transmitir esses saberes ao longo de todos esses anos? E como essa educação informal ainda sobrevive?

Alguns caminhos me pareceram mais adequados para compreender como ocorre esse processo educativo. Escolhi a abordagem qualitativa, para a compreensão do significado manifesto e latente dos comportamentos estudados. Considerando que o objeto deste trabalho são as inter-relações da cultura e da educação dos caipiras, classifico esta investigação como um estudo de caso etnográfico (André, 1995). Procurei, assim, dar à pesquisa um caráter interdisciplinar, com dados da memória, históricos, sociológicos e antropológicos, ancorados em um enfoque educacional. O trabalho baseou-se em pesquisas bibliográficas e de campo. Para realizá-lo escolhi a área territorial do município de São Luís do Paraitinga. Além de se situar no centro geográfico do Alto Paraíba, apresenta diversos aspectos da cultura caipira no comportamento de muitos de seus moradores. A povoação foi fundada em 1769, pelo sargento-mor (major) Manoel Antônio de Carvalho, a mando 
do capitão-general (governador) da Capitania de São Paulo, Luís Antônio de Sousa Botelho Mourão, o Morgado de Matheus.

Aliás, Holbwachs (2004) acredita que é nas cidades menores, um pouco afastadas das grandes correntes, que a vida é ainda regulada e ritmada como o era há um ou dois séculos. Ali as tradições são mais estáveis. Segundo ele, enquanto o grupo social evolui, a cidade, em seu aspecto exterior, muda mais lentamente. Assim, os hábitos locais resistem às forças que tendem a transformá-los e essa resistência permite perceber melhor até onde a memória coletiva tem um ponto de apoio.

Escolhi como sujeitos deste estudo dez pessoas - sete homens e três mulheres - com idades entre 70 e 90 anos, moradoras em três bairros e que sempre residiram na zona rural. Preferi as pessoas mais idosas dos bairros pois, de acordo com outros habitantes desses lugares, elas conservam boa parte das tradições da cultura caipira, tendo amplo conhecimento do contexto estudado.

\section{A formação da cultura}

Foi da Vila de São Paulo que, em 1645, partiu o bandeirante Jacques Félix para fundar Taubaté, a primeira povoação da região (Holanda, 2000; Ortiz, 1988). Já no final do século, havia também as vilas de Guaratinguetá e Jacareí. Embora fossem apenas três povoações, era a região paulista mais povoada (Prado Júnior, 1999; Trindade, 1977).

Faoro (2000) afirma que, ao dar organização política para uma vila, a autoridade real portuguesa não visava legalizar uma organização social já existente como resultado de uma povoação. Ao contrário, a vila só passava a existir oficialmente depois de autorizada. Foi o caso de São Luís do Paraitinga. Na época de sua fundação oficial, em 1769, já moravam no local cerca de 50 famílias e havia uma igreja, (Azevedo Marques, 1980). Antes dessa autorização oficial, o local era considerado não existente.

Os séculos XVI, XVII e XVIII representaram o estabelecimento do poder real e da expansão territorial paulista, e também a formação de um tipo de cultura e de uma etnia. O paulista, em grande parte, era o resultado do cruzamento de portugueses com as mulheres da terra, as indígenas. Dessa união nasceram mestiços em grande número, a quem se deu o nome de mamelucos (Saint-Hilaire, 1922). Nesses séculos, o estabelecimento de núcleos de povoação fez-se na base de famílias de sitiantes independentes, proprietários ou posseiros, mas todos com acesso à terra e numa quase igualdade de posição social (Franco, 1997).

Falando sobre a economia paulista dessa época, Simonsen (1957) afirma que a agricultura e o comércio eram incipientes e insuficientes até para as necessidades da população. A mercadoria mais vendida para as outras capitanias era a marmelada. 
Esse estado de carência da Capitania de São Paulo pode ser percebido até hoje na arquitetura. Edificações antigas de Minas Gerais, Bahia, Pernambuco e do Rio de Janeiro apresentam requintes que denotam suas riquezas, ao passo que as igrejas, os casarões e sobrados urbanos ou mesmo as sedes de fazendas paulistas apresentam um estilo despojado.

De outra parte, não se cogitava o fortalecimento ou o respeito da cidadania dos moradores do município. Nessa época, três providências a que as autoridades sempre recorriam ameaçavam os moradores: os recrutamentos para o serviço militar, a prestação compulsória de serviços para o governo e a cobrança de impostos (Prado Júnior, 1999). Discorrendo sobre a atuação governamental no Brasil Colônia, Holanda (1997, p. 33) afirma: "As iniciativas, mesmo quando se quiseram construtivas, foram continuamente no sentido de separar os homens, não de os unir". Em face dessa situação, o povo reagia de duas formas: ou se embrenhando pelas matas, onde passava a morar com suas famílias (Simonsen, 1957), ou se comportando de uma maneira apática, sem qualquer tipo de colaboração com as autoridades (Faoro, 2000).

O próprio Morgado de Matheus, quando chegou a São Paulo e percebeu o comportamento arredio dos paulistas, comentou: "Este costume de viverem dispersos, metidos pelas roças, tem feito hábito, de sorte que só fazem gosto da solidão e para ela fogem" (Simonsen, 1957, p. 243). Quando da fundação oficial da Vila de São Luís do Paraitinga, seu fundador só conseguiu moradores para o local quando obteve licença especial do capitão-general, concedendo o privilégio de que durante dez anos os povoadores não seriam "chamados para soldados nem ocupados em outro algum serviço ou emprego alheios a sua vontade" (Trindade, 1977, p. 12). Porém, para Cândido (1971, p. 62-63 e 71), o isolamento dos caipiras, vivendo em bairros rurais, era apenas aparente. Na realidade, as famílias tinham como ponto de referência de sua vida social não as sesmarias ou os sítios, mas os bairros, que se tornaram a estrutura fundamental da sociabilidade do caipira. "O termo 'bairro' parece estar ligado diretamente à área caipira, não ocorrendo, ao que eu saiba, noutras regiões do Brasil", acentua o autor.

Comentando a afirmação sobre a singularidade da vida comunitária do caipira, centrada no bairro, Queiroz acha que Cândido mostrou como era ilusória a primeira impressão de isolamento dos caipiras, morando cada família em suas terras. Na verdade, ela afirma, essas famílias estavam presas a uma organização de vizinhança, o bairro rural. Ainda de acordo com essa autora, no passado a área de influência caipira cobriu todo o território paulista. E considera o que chama de "civilização caipira" como a "forma mais antiga de civilização e cultura da classe rural brasileira, constituída desde os primeiros tempos da colonização" (1973, p. 8). No final do século xvıII a cultura caipira já estava consolidada. 
Mas o que significa o termo "caipira"? As diversas fontes que consultei não chegam a um consenso sobre a origem etimológica dessa palavra (Ferreira, 1986; Câmara Cascudo, 1972; Amaral, 1955) e apresentam versões diferentes e até contraditórias. Neste texto uso o termo "caipira" com o mesmo sentido que lhe dá Cândido (1971), ou seja, para designar os aspectos culturais dos descendentes dos antigos moradores da zona rural do estado de São Paulo. Assim, o termo "caipira" significa aqui o grupo social ou a pessoa portadora dos traços distintivos da cultura caipira.

\section{O começo das mudanças}

Tratando das mudanças na conjuntura, que acabaram tendo grande impacto no modo de vida do caipira, Prado Júnior (1999) considera que no século xIx se situa a etapa decisiva para a formação do Brasil. As inovações foram chegando lentamente, até que o café se tornasse uma cultura de exportação e fosse um fator decisivo para a economia e a vida social da região. Até as primeiras décadas desse século, muitos costumes dos moradores ainda eram praticamente os mesmos dos três primeiros séculos da história brasileira, predominando uma sociedade com muito pouca mobilidade social (Shirley, 1977).

A casa dos caboclos paulistas no início do século xIx era feita de pau a pique, como no início da colonização do Vale do Paraíba, há mais de 150 anos. Os utensílios domésticos eram igualmente simples. Grande parte dos objetos utilitários era de origem indígena. Vasilhas como panela, gamela, esteira, rede, peneira, balaio, piquá, pilão, tigela, colher de pau, pote, moringa, talha, sabão de cinzas e cuia eram feitos de materiais nativos como taquara, taboa, barro, cambuca ou madeira. Às vezes eram enfeitados com pinturas ingênuas. Atualmente esses produtos estão quase desaparecidos.

As grandes mudanças na economia e nos costumes do Vale do Paraíba ocorreram, de fato, a partir de 1830, quando a monocultura cafeeira tomou conta da região. O café foi um fator decisivo para as modificações que ocorreram na legislação fundiária e nos costumes da sociedade. Foi com esse produto agrícola que começou uma forma incipiente de capitalismo e apareceram os primeiros hábitos de consumismo. Na economia, o café foi tão importante que, em 1850, excluído esse produto, o Brasil exportava menos que em 1800 (Faoro, 2000). E teve um grande impacto na demografia regional: em 1836 a população vale-paraibana era de 105.679 habitantes; em 1886, no apogeu do café, a região atingiu 338.537 moradores (Pasin, 2000). Nessa época os caipiras constituíam cerca de dois terços da população livre e eram mais numerosos que os escravos existentes (Franco, 1997).

Os caipiras também foram envolvidos pela engrenagem de mudanças que ocorreram na região. A Lei n. 601, de 18 de setembro de 1850, conhecida como “Lei 
da Terra", acabou com o regime de posses, que era a forma como, tradicionalmente, eles ocupavam as terras em que moravam. Isso consolidou a tendência de concentração da propriedade agrária, que vinha se configurando desde a chegada desse arremedo de capitalismo, trazido pelo café (Faoro, 2000).

O mundo simples e unitário existente nos três primeiros séculos da formação do paulista passou a ser coisa do passado. Da nova ordem econômica e fundiária surgiram quatro categorias: o fazendeiro, dono de um latifúndio, onde predominava a monocultura de exportação; o sitiante, que continuava produzindo a costumeira agricultura de subsistência, com alguns produtos excedentes para o mercado; o agregado, que residia nas fazendas ou nos sítios, ocupando como parceiro ou meeiro parte das terras com lavouras e criações; e o camarada, um trabalhador sem vínculo empregatício, geralmente recebendo como diarista. Para Queiroz, a disseminação das grandes fazendas monocultoras de café contribuiu para a desorganização das tradições dos grupos de vizinhança. Mas isso não desenraizou os costumes caipiras, uma vez que, verificada a decadência dessa monocultura, as fazendas foram outra vez divididas em sítios e a "civilização caipira voltou a florescer no Vale do Paraíba e adjacências" (1973, p. 137).

Em contrapartida, nas últimas décadas do século xix e nas primeiras do século $x x$, já se observava uma nítida urbanização dos investimentos econômicos. Em face das mudanças na economia dessa época, o setor rural deixou de ser o que apresentava as maiores oportunidades de investimentos. As melhores remunerações para o capital agora estavam nas cidades. $\mathrm{O}$ dinheiro dos investidores, antes empregado nas lavouras, passou a ser canalizado para os grandes centros. Isso se refletiu na expansão das atividades comercial, bancária e industrial. Atividades urbanas, portanto.

Com isso, o caipira paulista passou a sofrer, no próprio estado onde vivia, um preconceito cultural. Em outras palavras, o preconceito contra o caipira, que acabou se transformando num estereótipo, foi consequência das mudanças que vinham ocorrendo na economia do país. Segundo Martins (1975, p. 4, 26 e 87), a afirmação da superioridade do modo de vida urbano sobre o rural exprimiu-se culturalmente na construção de estereótipos negativos sobre o morador da zona rural. O caipira seria um indivíduo ingênuo, preguiçoso, desnutrido, doente, maltrapilho, rústico e desambicioso: "Esse estereótipo encontrou sua melhor descrição no Jeca Tatu, de Monteiro Lobato, e que tem sua contrapartida nas virtudes contrárias, atributos do homem urbano".

Almeida (1987) considera que, ao classificar o caipira como raça inferior, a ideologia de Monteiro Lobato mostrava seu inconformismo com um grupo social que resistia em deixar seus costumes seculares para se integrar na cultura europeizada, 
recém chegada com a industrialização. Queiroz (1973, p. 87 e 112), por sua vez, afirma que descrevê-los como estando à margem da realidade social do Estado é colocar o problema de maneira falsa, "já que tais sitiantes estão plenamente integrados nela, sendo que sua participação se regula pelos princípios da civilização caipira e não pelos princípios da civilização moderna". E observa que não se deve esquecer que "a vida social do Estado de São Paulo foi, em tempos mais remotos, totalmente governada pela antiga civilização caipira".

O café resistiu na região até a década de 1920. A partir daí, o Vale do Paraíba começou a passar por outras mudanças, com a chegada da pecuária leiteira extensiva, a ocupação das vargens do Rio Paraíba com plantações de arroz, a transformação urbana e cultural das cidades e as primeiras tentativas de industrialização.

A produção de leite trouxe para a região melhores estradas, por onde passavam os caminhões que faziam o transporte do produto. Os "leiteiros", como eram conhecidos esses veículos, promoveram a quebra do isolamento dos moradores dos bairros rurais. Além de não mais depender das limitações do armazém do bairro, os caipiras passaram a ter acesso aos remédios das farmácias, a eventuais consultas médicas nas santas casas e em centros de saúde; as mulheres puderam comprar suas roupas e móveis nas lojas, modificando seu modo de vestir e mobiliar suas casas; e os agregados e camaradas que se sentiam prejudicados passaram a recorrer às repartições da Justiça para resolver seus problemas trabalhistas.

\section{Educação: transmissão de cultura}

Durante muito tempo se pensou que culturas de sociedades iletradas ou ágrafas eram menos complexas ou menos elaboradas que as de sociedades em que a escola havia se desenvolvido. Hoje, porém, considera-se que os conhecimentos passados pela educação tradicional, com base no saber oral, como o dos caipiras ao longo da história paulista, são comparáveis àqueles veiculados pela escrita. Dessa forma, se certas sociedades não se utilizam da linguagem gráfica para a transmissão de seus saberes é porque o modo de vida de tais indivíduos não lhes apresentou tal necessidade e não porque sua aptidão mental fosse inferior. Atualmente, a capacidade simbólica e os padrões de todas as culturas humanas são considerados igualmente abstratos, significativos e capazes de dar respostas úteis aos problemas de compreensão do mundo (Costa, 2002).

Por isso busquei na memória coletiva, nas entrevistas com os sujeitos desta pesquisa, os elementos para a análise do processo educativo usado pelos caipiras para transmitir seu instrumental de adaptação ao ambiente físico e social e de manutenção da coesão do grupo, através do tempo de sua existência. Os entrevistados têm 
em comum o fato de sempre terem morado na zona rural de São Luís do Paraitinga, assim como todos os seus ascendentes dos quais se lembram. Por esses contatos pude inferir que três elementos foram (ou são) fundamentais para o processo educativo informal dos caipiras: o trabalho, a religiosidade e, entrelaçada com os dois primeiros, a solidariedade do grupo.

\section{0 trabalho}

Para se compreender o valor que o caipira dá ao trabalho é necessário olhar para a sua morada e como ela é usada. A casa é considerada pelo morador tradicional do Alto Paraíba o local onde se concentra seu esforço cotidiano de manutenção da vida dos familiares que ali residem. Por isso percebi em todas as casas da zona rural que visitei que são, ao mesmo tempo, espaços de convivência e de descanso, e também de trabalho. Brandão (1999, p. 112-113) descreveu a casa do caipira como "uma extensão doméstica do trabalho familiar" e afirmou que nela "todos os espaços são feitos para serem úteis - e não cômodos".

Boa parte das tarefas realizadas fora do recinto da casa é dividida. O pasto e a mangueira de ordenha, as terras da lavoura e todos os outros locais de criação e trato do gado e dos cavalos são espaços simbolicamente masculinos. Os homens veem esses locais como seus ambientes próprios de trabalho e ganho econômico. Apenas em casos excepcionais as mulheres da casa ajudam os homens nesses serviços. Mas, se o campo é um domínio masculino, o terreiro é um espaço mais feminino. Ali os homens cuidam das tarefas que fazem a mediação entre o espaço masculino do pasto e da lavoura e o espaço feminino da casa. Eles lidam com o paiol de milho, consertam seus artefatos de trabalho, batem o feijão, debulham o milho e preparam as rações para os bois de arado e cavalos. Mas o domínio das mulheres sobre o terreiro é mais acentuado. Ali elas cuidam do pomar, da horta e dos animais domésticos. Elas podem dividir com os homens da família os cuidados e o ganho com os porcos e o queijo. Mas os rendimentos obtidos das aves, dos ovos, do requeijão, da manteiga e os eventuais produtos da horta e do pomar são invariavelmente de domínio da mulher. Assim, ao passo que os ganhos auferidos com o leite, com as plantações de cereais e com a venda de animais são considerados próprios dos homens, o que se apura com a venda de produtos do terreiro pertence tudo para as mulheres que, dessa forma, mantêm certa independência econômica dentro da família.

De acordo com diversos depoimentos, antigamente os brinquedos das crianças já eram uma forma de preparação para o trabalho. Brincava-se no terreiro da casa. Um dos brinquedos dos meninos era imitar o comércio de mercadorias, como ocorria nas vendas e nos armazéns dos bairros. De acordo com o mais idoso dos entrevistados, 
Usavam terra vermelha e terra branca para dizer que eram cereais e barro em forma de quadradinhos era rapadura; areia branca virava açúcar ou sal. Faziam balancinhas para pesar as mercadorias. Enquanto um menino fingia que era o dono da venda os outros compravam, usando como dinheiro cacos de tigela. Também faziam urupuca, bolas feitas de panos costurados e casinhas cobertas com folhas de bananeiras.

Os adolescentes tinham outras brincadeiras: "Brincavam com bola de pano, costurada bem costuradinha. Também de correr cavalhada. Às vezes nós juntava um terninho, a rapaziadinha nova e ficava pastejando em pelo no cavalo", disse um informante de outro bairro.

Já as meninas, segundo uma das entrevistadas, tinham suas próprias maneiras de brincar: "As mais novas faziam bonecas de sabugo de milho; depois que cresciam mais um pouco aprendiam, com as mães ou com as costureiras do bairro, a fazer bonecas de pano. Também brincavam de casinha e faziam peteca de palha de milho e penas de galinha. Uma das brincadeiras que elas mais gostavam era inventar de fazer casamento".

Brincar de fazer casinha, atividade comum a meninos e meninas, era realmente uma maneira de imitar as atividades dos adultos, quando estes faziam suas casas de pau a pique (ou taipa da mão).

Mas o tempo reservado ao lazer da infância era curto. A criança logo era encaminhada para o aprendizado do trabalho. Como as escolas na zona rural eram poucas, restava às famílias caipiras o secular currículo educacional que, embora nunca fosse escrito, sempre foi usado para a transmissão dos instrumentos de adaptação ao meio físico e para as suas relações sociais e simbólicas.

Assim, as crianças de ambos os sexos, desde que nasciam até pelo menos a idade de 8 anos, ficavam sob os cuidados das mulheres da casa: a mãe, as irmãs mais velhas e, eventualmente, as avós. As brincadeiras juntas no terreiro logo começavam a estabelecer espaços, reinações e tratamentos diferenciados. As meninas iam se subordinando plenamente às mulheres, com quem começavam a aprender os serviços considerados femininos. Já os meninos escorregavam pouco a pouco para a companhia dos homens - do pai e dos outros irmãos -, quando eles estivessem em casa ou no terreiro.

E aí estava justamente o núcleo desse currículo informal, mas muito eficiente. O fato de as meninas acompanharem as mães e os meninos o pai significava, na prática, entrar para o aprendizado das tarefas e profissões que iriam exercer no futuro. Entre os 8 e 12 anos as crianças não exerciam uma profissão: elas executavam as tarefas junto com os adultos, como aprendizes. Estavam, na realidade, se preparando para o trabalho, numa espécie de sistema curricular, nessa pedagogia desenvolvida pelos paulistas da zona rural durante quase quatro séculos. 
Um dos entrevistados explicou esse processo de aprendizagem:

\begin{abstract}
Os meninos aprendiam vendo os pais trabalhar. Quando ia barrear uma casa ou quando ia trabalhar com uma junta de bois, arrastando pau no mato. Eu ia atrás de meu pai lá. O menino ia vendo e quando ficava hominho já estava sabendo o que o pai fazia. Quando ele começava a trabalhar, ele não ia aprender: ele já sabia de tudo o que devia fazer. Eu peguei [no serviço] com 13 anos já sabendo de tudo. Daí não tinha nada que meu pai ensinar. Era bonito aquele tempo; era gostoso demais.
\end{abstract}

Isso significa que por volta dos 13 anos de idade eles chegavam ao estágio de prontidão profissional: já entendiam todos os serviços que se faziam na zona rural e podiam continuar acompanhando os pais. Só que então como profissionais qualificados para o trabalho.

Dessa forma, esse currículo colocado em prática desde tempos imemoriais previa que os garotos entre 8 e 10 anos fossem com os pais para a roça. Os pais iam ensinando as técnicas de carpir, roçar, plantar. Plantavam milho, feijão, mandioca, cana. Essas plantações quase todo mundo tinha para o gasto. Além dos serviços da lida agropastoril, os meninos e rapazes aprendiam a fazer certos instrumentos de trabalho, como o escrassador de moer cana para fazer a rapadura a fim de adoçar o café. Os que levavam jeito aprendiam o que hoje é chamado de artesanato, como chapéu de palha e instrumentos usados nas tropas, como cargueiros, bruacas, jacás e o conserto de arreios. Com 13 anos o rapaz já era considerado um trabalhador formado, capaz de carpir uma quadra ou tirar uma empreitada. Era costume que os rapazes trabalhassem para os pais pelo menos até os 21 anos de idade. “Não é que nem agora, que os filhos não trabalham mais para os pais. Principiam a trabalhar e já é cada um para si. Naquele tempo, capaz, não era assim!", lamentou um de meus entrevistados.

Nessa mesma faixa de idade as meninas começavam a aprender os trabalhos domésticos simbolicamente considerados femininos. Dos 8 anos em diante as mães já iam ensinando, mas elas só se afirmavam por volta dos 12 anos. Mais ou menos na idade em que os rapazinhos também completavam seu aprendizado. No início da adolescência elas já estavam aptas a tomar conta da casa, quando a mãe se ausentava. Em casa, as meninas começavam aprendendo a fazer roupa de boneca. Depois, aprendiam a costurar roupa de gente grande. Em muitas casas havia máquinas de mão para costurar. Se os pais precisavam, as meninas ajudavam a carpir, roçar e limpar as plantas. Quando elas iam para a roça e na irmandade tinha homem e mulher, os irmãos é que davam as explicações às irmãs. Eram também as irmãs e os irmãos mais velhos que falavam para as meninas que iam ficando adolescentes sobre assuntos de "namoração".

Para as meninas-aprendizes ficava ainda a tarefa de cuidar das criações no terreiro: porco, cabrito, galinhas e as outras aves. Além disso, eram elas que deviam 
distinguir os vegetais: aqueles que serviam para remédio - já que era próprio das mulheres o cuidado dos doentes - das plantas que tinham outras utilidades, como para fazer azeite, sabão ou vassouras, além daquelas consideradas nocivas para a saúde. Todas as pessoas que eu entrevistei me disseram que a principal coisa que uma menina precisava aprender era cozinhar. Desde criança elas iam aprendendo os pratos típicos da cozinha caipira. Nessa sociedade ágrafa, de poucas, raras escolas, as receitas eram guardadas, na maior parte das vezes, de cor. Daí a importância da memória. Mas o mais idoso de meus entrevistados lamentou: "Agora as moças se casam e não sabem nem cozinhar. Naquele tempo não era assim, não. Os pais e as mães ensinavam e os filhos aprendiam. A gente que viu tudo isso, agora até parece um sonho".

\section{A religiosidade}

Fiquei também convencido de que outro instrumento fundamental na educação dos caipiras foi a religião. Ou melhor, a expressão de uma determinada forma de religiosidade.

As crianças começavam a aprender as primeiras noções de religião com o pai e a mãe. Mas praticamente toda a comunidade do bairro transmitia, na vida cotidiana, a sua religiosidade para as crianças. Depois elas iam ao catecismo na capela. As catequistas ou os capelães ensinavam, além as orações litúrgicas, também as suas rezas tradicionais.

Todos os entrevistados falaram, demonstrando saudades, das ladainhas cantadas a duas ou três vozes, oração que eles ainda têm em grande conta e a que mais gostavam de rezar. Era uma prece que se fazia coletivamente, servindo para incutir nas crianças o espírito de vida comunitária, por intermédio da religião. Hoje não se canta mais a ladainha nas capelas dos bairros que visitei.

As crianças também aprendiam a fazer os instrumentos usados para as orações. As meninas, principalmente. Azeite de mamona, usado como combustível para a lâmpada votiva que se acendia em frente dos oratórios familiares; o terço de capiá, onde aprendiam a rezar as principais orações cristãs; e as lendas de fundo religioso, que tinham um sentido pedagógico. As crianças ouviam dos mais velhos e também contavam umas para as outras.

Holanda (1998), em Visão do paraíso, cita diversas lendas que tiveram origem na Europa medieval ou entre os índios que habitavam a Capitania. Até os anos de 1950 ainda eram contadas entre as crianças e os adultos da zona rural de São Luís do Paraitinga. Entre essas lendas estão as do saci, da lagarta que vira cuitelo, da flor de maracujá como símbolo da Paixão e dos ares milagrosos de alguns lugares, capazes de curar doenças. 
Talvez o mais forte traço medieval, que sobrevive entre os caipiras, seja a instituição do compadrio, que ocorre quando um casal convida outro para ser padrinho de seu filho. Os laços entre as famílias e as obrigações que o casal de padrinhos assume - que vão do dever de dar educação religiosa a substituir os pais, adotando a criança, em caso de dissolução ou carência da família paterna - remontam ao direito consuetudinário, vigente no início da dinastia afonsina, em plena Idade Média (Faoro, 2000).

Entretanto, todas as pessoas que entrevistei consideram que atualmente está muito difícil para os pais, avós e mesmo para a comunidade do bairro serem os primeiros catequistas das crianças. Afirmam que os motivos são vários. Culpam as influências vindas das cidades, principalmente a televisão que, acreditam, veicula maus exemplos dentro da família e a presença de drogas entre a juventude.

Essa transição de comportamentos é experimentada até por aqueles que jamais moraram fora dos sertões. A sedução do modo de vida da cidade chega aos lugares mais afastados da zona rural do Alto Paraíba. Até os divertimentos promovidos no pátio da capela durante as comemorações festivas, os antigos moradores consideram fatores negativos para a educação religiosa e comunitária. “Tem divertimento para mim que é uma profanidade numa festa de igreja, como é o forró, que antes não existia. E para tirar renda, em qualquer festa já é o bingo. Isso aí acabou com tudo. Eu não participo e, de fato, não gosto", reclamou um dos entrevistados que por muitos anos foi o capelão daquele bairro.

Uma síntese da religiosidade dos caipiras aparece na realização da Festa do Divino Espírito Santo. Nenhuma das manifestações lendárias ou festivas do Alto Paraíba expressa tão bem a sobrevivência do arquétipo dessa cultura como essa comemoração religiosa. Nesse evento os caipiras, ao prestar culto à Divindade, também realizam um trabalho solidário, envolvendo um grande número de pessoas, que nada recebem pelos serviços que prestam. Essa participação, ao longo do tempo, deve ter sido um instrumento para a transmissão de seus costumes para as gerações mais novas e para e educação das crianças e dos jovens em suas tradições comunitárias.

\section{Solidariedade}

Junto com o trabalho e a religiosidade praticados nos bairros caipiras, outro traço marcante dessa cultura é a ajuda mútua ou participação comunitária. Pesquisadores veem nesses comportamentos a sobrevivência de diversas vertentes culturais e étnicas, em especial a influência da época da aculturação e adaptação entre os costumes portugueses e os de origem indígena (Holanda, 1997 e 2000; Shirley, 1977; Ribeiro, 1995). 
As tradições de participação comunitária expressavam-se de diferentes maneiras. Podiam envolver apenas algumas pessoas, como no caso de uma mulher que se encarregava de cuidar de uma parturiente e assumir todos os cuidados domésticos, durante o período em que a mulher que deu à luz não podia trabalhar; mobilizar dezenas de pessoas, como num mutirão de preparo de pasto, construção de uma estrada ou ponte, na barreação de uma casa para os noivos ou reformar a morada de um idoso ou família necessitada; ou também para construir ou na manutenção da capela do padroeiro do bairro.

Assim como as lendas antes referidas, os costumes de ajuda mútua apontam, por trás de instituições sociais aparentemente singelas, a existência de um mecanismo social complexo, tecido ao longo de muitos anos e fruto de uma transmissão educacional tão eficiente que conseguiu sobreviver por séculos, atravessando muitas gerações e diversos períodos da história brasileira. Aliás, segundo pude perceber, uma das principais finalidades desses costumes era transmitir os conhecimentos para manter suas tradições. Isso se realizava por intermédio da ajuda organizada entre membros de uma ou diversas comunidades caipiras. Em outras palavras, as formas tradicionais de participação comunitária eram maneiras informais que os caipiras possuíam para educar seus filhos. As crianças eram levadas, desde os 8 anos, a cada um desses eventos.

As duas principais formas de participação comunitária eram a troca de dias e o mutirão. Na troca de dias, diversas famílias reuniam-se e iam trabalhar para uma outra na colheita, na limpa de pastos e nas demais atividades agropastoris. A família beneficiada ficava obrigada a trabalhar para todas as famílias que a haviam ajudado. Era uma troca. Ninguém recebia e ninguém se negava a cumprir sua obrigação de pagar o dia de trabalho recebido como ajuda. Todos os entrevistados me afirmaram: a troca de dias não existe mais na zona rural do Alto Paraíba.

Já o mutirão é uma prestação voluntária e gratuita de serviços entre moradores dos bairros dos municípios. Ninguém se obriga. E não há a necessidade, para quem recebeu o serviço, de trabalhar para quem lhe prestou o trabalho. $\mathrm{O}$ pagamento é feito em forma de festa, com muita comida, bebida, café com biscoito e cantoria, durante a prestação do serviço. E termina sempre em festa. Com apenas isso, aqueles que vão trabalhar se sentem bem pagos. De acordo com Willems (1947), não há dúvida de que essas instituições dão uma força de resistência à estrutura social, que outras sociedades, baseadas exclusivamente no trabalho assalariado, não possuem. Pelos depoimentos de moradores que participam de mutirões em diversos bairros, essa prática continua sendo realizada, embora mais raramente. As pessoas reúnem-se para a conservação de capelas e das casas de pessoas carentes. O trabalho comunitário de limpa de pastos é feito praticamente como há cerca de 50 anos. 
Muita coisa mudou na estrutura agrária da região. O município de São Luís do Paraitinga empobreceu. A zona rural continua a esvaziar-se. Com isso, muitos costumes ligados ao mutirão desapareceram. A abertura e manutenção de estradas é um deles, agora quase totalmente assumidas pela Prefeitura, que para isso mantém funcionários, conhecidos como conserveiros. O barreamento de casas de pau a pique para os noivos não existe mais. $\mathrm{O}$ material usado nas novas construções é a alvenaria: tijolos ou blocos de cimento. E o trabalho é feito, geralmente, por pedreiros profissionais.

A cobertura de sapé, tão comum até os anos de 1970, também tão existe mais. Aliás, quem passa pelas estradas do Alto Paraíba é muito difícil ver, esparramado pelos pastos, um pé de sapé, vegetação nativa tão comum há algumas décadas nessa região de Mata Atlântica. Assim como muitos aspectos da cultura e da educação dos caipiras, o sapé parece estar em extinção.

\section{A roça na cidade}

A decadência da pecuária leiteira foi o fator econômico mais importante na história recente de São Luís do Paraitinga, tornando-se um acontecimento decisivo para os fatos que ocorreram no município nos últimos 40 anos. Nesse período a vida do caipira mudou muito. Com isso, a partir da década de 1970, ocorreu uma modificação fundamental na posse da terra e na produção rural. Os sítios e as fazendas foram sendo vendidos para os moradores das grandes cidades. A maioria passou a utilizar as propriedades para lazer ou com plantações de eucalipto. Os empregados que ainda existiam foram sendo dispensados e o local acabava ficando sob a responsabilidade de apenas uma família. Esses passaram da condição de agregados para a de caseiros.

A produção de leite no município diminuiu muito. E a área destinada à produção de eucalipto aumentou demais. Outra mudança fundamental no perfil econômico dos habitantes de São Luís do Paraitinga: boa parte desses trabalhadores, antes de se mudar para a zona urbana, era de pequenos sitiantes e meeiros. É abandonando a posição de parceiro ou agregado na zona rural e se tornando assalariado rural ou urbano que o trabalhador de origem caipira consegue se integrar no contexto econômico. Assim, de produtores passaram a ser empregados e consumidores na cidade.

$\mathrm{O}$ ambiente de uma cidade pequena permite aos que migram da zona rural alguma forma de recriação de seu mundo de origem. A transposição de costumes manifesta-se na precariedade da arquitetura e das instalações de suas casas, localizadas principalmente na periferia. E na reinvenção de tradições, como nas danças das 
"companhias de moçambique" e "congadas", nas folias de reis e em outras manifestações culturais que há uns 50 anos só existiam na roça. Seria, talvez, uma forma de valorizar suas expressões culturais e religiosas, fazendo delas instrumentos de readaptação. Nota-se que em quaisquer desses grupos existem crianças e jovens como dançadores, instrumentistas ou representando alguma figura de destaque.

O êxodo rural parece ser uma das principais causas na inversão da distribuição de moradores. Em 1940, dos 11.127 moradores, 1.164 residiam na zona urbana e 9.963 estavam na zona rural (IBGE, 1948). É interessante notar que ao passo que no Censo de 1970 se constatou que a maioria da população brasileira passara a morar na zona urbana (Durhan, 1973), em São Luís do Paraitinga isso só acorreu 20 anos depois, pelo recenseamento de 1991. De acordo com a estimativa de 2005 do IBGE, o município conta com 10.417 habitantes, sendo 6.143 (59\%) na cidade e 4.274 (41\%) morando na roça.

\section{Rito de saída}

Ao terminar suas narrações lamentando o desaparecimento dos costumes sempre usando expressões que demonstram saudades do passado e uma melancolia da situação presente -, os entrevistados não estariam indicando que eles constatam que a educação que sempre foi utilizada para a transmissão de sua cultura gradualmente vem perdendo o significado para as novas gerações?

O futuro de uma cultura depende da capacidade do grupo social onde ela sobrevive de continuar transmitindo sua educação tradicional. Todos os entrevistados, por um ou outro motivo, tiveram pouca escolaridade. Entretanto, isso não teve grande impacto nas suas formações. Nem impediu que, depois de adultos, integrassem-se na vida econômica do município. Tanto que todos são pequenos proprietários de terras, das quais, de alguma forma, tiraram o seu sustento. Para a educação tradicional caipira, a criança ou o adolescente pouco precisava de uma sala de aula, livros, professores e outras metodologias pedagógicas. Pelo contrário, eles, em suas brincadeiras e nos seus trabalhos, precisavam de contato livre com suas famílias e com os moradores do bairro onde moravam.

Só que agora eles não podem tocar essa empreitada apenas com os instrumentos e a metodologia que no passado utilizavam com eficácia. As transformações estruturais pelas quais o país passou, com o estabelecimento de uma ordem econômica capitalista, determinaram que a escola acabasse ocupando diversos papéis que antes cabiam à família e à comunidade do bairro realizar para a educação das crianças. Apesar disso, a população escolar diminuiu. Em 1968 existiam 22 escolas rurais com 424 alunos, em classes que iam da $1^{\underline{a}}$ à $3^{\underline{a}}$ série. Com a municipalização foram 
criados, a partir de 2005, quatro núcleos escolares, cada um reunindo as crianças dos bairros adjacentes. Mesmo existindo, em todos, curso completo de Ensino Fundamental, a matrícula diminuiu, pois somam apenas 324 .

No interior da família e da comunidade caipira o processo de educação não é um ato passivo, mas um processo ativo que interfere no indivíduo, levando-o a recriar o aprendido de acordo com suas necessidades e condições materiais de vida. Por isso a escola poderia levar à compreensão das realidades produtoras dessas formas de vivências sociais, permitindo que as culturas escolar e caipira se interpenetrassem, sem perder suas identidades.

Pluralismo significa diálogo com outras culturas a partir de uma cultura que se abre às demais. A meu ver, é justamente disso que as escolas destinadas aos caipiras precisam: da promoção de políticas que contemplem a diversidade cultural; de currículos que preparem as crianças e os adolescentes da zona rural para o exercício da cidadania e de programas que busquem a compreensão da educação própria dessa cultura tradicional.

\section{Referências}

ALMEIDA, J. Festas em São Luís do Paraitinga na passagem do século: 1885-1915. 1987. 723f. Tese (Doutorado) - Instituto de História, Universidade de São Paulo, São Paulo.

AMARAL, A. O dialeto caipira. 3. ed. São Paulo: Anhembi, 1955.

ANDRÉ, M.E.D. Etnografia da prática escolar. Campinas: Papirus, 1995.

AZEVEDO MARQUES, M.E. Apontamentos históricos, geográficos, biográficos, estatísticos e noticiosos da Província de São Paulo. Belo Horizonte: Itatiaia; São Paulo: Edusp, 1980.

BRANDÃO, C.R. O caipira de São Paulo. São Paulo: Brasiliense, 1983.

BRANDÃO, C.R. O trabalho de saber: cultura camponesa e escola rural. Porto Alegre: Sulina, 1999.

CÂMARA CASCUDO, L. Dicionário do folclore brasileiro. Brasília, DF: Instituto Nacional do Livro, 1972.

CÂNDIDO, A. Os parceiros do Rio Bonito: estudos sobre o caipira paulista e a transformação dos seus meios de vida. 2. ed. São Paulo: Duas Cidades, 1971.

COSTA, C. Sociologia: introdução à ciência da sociedade. 2. ed. São Paulo: Moderna, 2002. 
DURHAN, E.R. A caminho da cidade: a vida rural e a migração para São Paulo. São Paulo: Perspectiva, 1973.

FAORO, R. Os donos do poder: formação do patronato brasileiro. 10. ed. São Paulo: Globo; Publifolha, 2000.

FERREIRA, A.B.H. Novo dicionário da Língua Portuguesa. 2. ed. Rio de Janeiro: Nova Fronteira, 1986.

FRANCO, M.S.C. Homens livres na ordem escravocrata. 4. ed. São Paulo: unEsP, 1997.

HOLANDA, S.B. Raízes do Brasil. 26. ed. São Paulo: Cia das Letras, 1997.

HOLANDA, S.B. Visão do paraíso: os motivos edênicos no descobrimento e colonização do Brasil. 6. ed. São Paulo: Brasiliense, 1998.

HOLANDA, S.B. Monções. 3. ed. São Paulo: Brasiliense, 2000.

HOLBWACHS, M. A memória coletiva. São Paulo: Centauro, 2004.

INSTITUTO BRASILEIRO DE GEOGRAFIA E ESTATISTICA (IBGE). Sinopse estatística do Município de São Luís do Paraitinga. Rio de Janeiro, 1948.

MARTINS, J.S. Capitalismo e tradicionalismo: estudos sobre as contradições da sociedade agrária no Brasil. São Paulo: Pioneira, 1975.

ORTIZ, J.B. São Francisco das Chagas de Taubaté. Taubaté: Prefeitura Municipal de Taubaté, 1988.

PASIN, J.L. A formação histórica e cultural do Vale do Paraíba paulista. Boletim do Instituto de Estudos Valeparaibanos, Guaratinguetá, n. 119, p. 3-6, abr. 2000.

PRADO JÚNIOR, C. Formação do Brasil contemporâneo. 23. ed. São Paulo: Brasiliense, 1999.

QUEIROZ, M.I.P. Bairros rurais paulistas: dinâmica das relações bairro rural-cidade. São Paulo: Duas Cidades, 1973.

RIBEIRO, D. O povo brasileiro: a formação e o sentido do Brasil. São Paulo: Cia das Letras, 1995.

SAINT-HILAIRE, A. S. Paulo nos tempos coloniaes. São Paulo: Monteiro Lobato, 1922.

SHIRLEY, R.W. O fim de uma tradição. São Paulo: Secretaria de Cultura, Ciência e Tecnologia do Estado de São Paulo; Perspectiva, 1977.

SIMONSEN, R.C. História econômica do Brasil: 1500-1820. 3. ed. São Paulo: Nacional, 1957. 
A educação do caipira: sua origem e formação

TRINDADE, J.B. No caminho do Paraitinga. São Paulo: Secretaria de Cultura, Ciência e Tecnologia do Estado de São Paulo, 1977.

WILLEMS, E. Cunha: tradição e transição em uma cultura rural do Brasil. São Paulo: Secretaria da Agricultura do Estado de São Paulo, 1947.

Recebido em abril de 2009.

Aprovado em março de 2010. 